\title{
Литература
}

1. ARINC 651. Руководство по проектированию интеграпьной модульной авиационной электроники: Пер англ. США. - Мериланд, 1991. - $278 \mathrm{c}$.

2. Ниформациониые технологии в наукоемком машиностроении// Под общ. ред. А. Г. Братухина. - К Техніка, 2001. - $728 \mathrm{c}$.

3. Современнье концепции управления проектом компьютерно-интегрированной логистической поддержк внртуального авиапредприятия на жизненном цикле /В. М. Воробьев, А. Д. Киселев, П. Р. Левковец и д //Проблеми інформатизації та управління: 3б. наук. пр. - К.: НАУ, 2004. - Вип. 11.- С. 96 - 101

4. Математическая модель и алгоритм синтеза оптимального комплексировағия авионики перспективнь воздушных судов на стадии замысла /В. М. Воробьев, А. Д. Киселев, В. А. Захарченко и д //Автонляховик України. - К.: НТУ, 2005. - №1 - С.56-63.

5. Воробъев В. М., Вуйцик В. Идентификация динамических характеристик систем автоматическо управления полетом в условнях серийного авиазавода /Комплексная автоматизация промышленности: C науч. тр. МНТК. - Врошлав: ВІТА, 1989. - С.309 - 313.

6. Воробъев В. М., Вуйцик В. Критерни качества снстем автоматического управпения полетом воздушнь судов //Вопросы оптимального обслужквания и ремонта АиРЭО ВС ГА: Сб. науч. тр. - К.: КИНГА, 1985 C. $83-87$

7. Прямий метод оцінки якості в задачах оцінки технічного стану систем автоматичного керуван авіадвигунами. / Єнчев С.В. // Проблеми інформатизації та угравління: 3б. наук. пр. - Вип.2(20). - К НАУ, 2007. - C.67-72.

8. Формирование обобщенного показателя качества функционирования логико-динамицеских систе авионики в задачах идентификацил интегрированных автоматизированных систем управлени авиапредприятий / Воробъев В.М., Захарченко В.А., Енчев С.В., Кондратенко С.В. // Електроніка снстемн управління. - 2005. - Bн11. 1.- С. $106-117$

УДК $62-52$

\section{СИСТЕМЫ ГАРАНТИРУЮЩЕГО УПРАВЛЕНИЯ: НАУЧНЫЕ ОСНОВЫ}

\author{
Хобии В.А., д.т.н., професор \\ Одеская нацинальная академия пнщевьх технологий, r. Одесса
}

Дия класса САУ, реализуюици функиио гарантированного соблюдения установленных регламентам ограничений иа режимиые переменные объекта, рассиотрены их научиые основы, вкпючаюице диалекти возникновения. взсимодействие с САУ, реализуюицими функиии регулирования и оптимизапии, копцепцию пеоретическую базу построения. Приведены результаты исследований. Такой класс систем позииионируети как новый и назван системали гарантируюичего управления.

For ACS' class realising function of the guaranteed observance established by regulations on object's regin variables restrictions, their scientific bases including dialectic of the occurrence, interaction with the ACS realisin functions of regulation and optimisution, the concept and construction theoretical base are considered. There at results of the researches. Such systems' class is positioned as new and named by guaranteeing management systems.

Ключевые слова: система автоматического управления, объект управления, ограничение, гарантировани оптимизация, экстремальное регулирование.

\section{Введение}

Нарушения режимов работы объектов управления, связанные с выходами режимных переменных установленные регламентами ограничения, приводят к их аварийным остановам, потерям сырья, браку готово продукции, персрасходу энергоресурсов, быстрому износу оборудования, необходимости имсть большой ште технологического персонала и ремонтных служб. Проблема усугубляется, если нанболее эффективные режим близки к предельно допустимым, а объекты управления (ОУ), являются существенно нестационарным подвержены интенсивным неконтролируемым возмуцениям, имегот запаздывание в каналах управления

Одним из эффективных путей решения этой производственной проблемы является совершенствован систем автоматического управления (САУ). Однако, совершенствование традиционных функций САУ (преж 
всего - функций регулирования и оптимизации) принципиалын ле может решить гроблемы. В пекоторых случаях она может быть «смягчена», например, гри повышении качества регулирования. В некоторых наоборот. Например, реализация функции оптимизации эту проблему обостряет. Поэтому, совершенствовапие САУ должно идти по пути расширения состава реализуемых функций.

Одной из таких функший, актуальность которой была обоснована выше, является функция гарантировання, т.е. гарантированного, с наперед заданной вероятностью соблюдения ограпичений, установлсниых регламентами. Цель данной статьи системно рассмотреть научные основы САУ, реализующих эту функцию, названных системами гарантирующего управления (СГУ).

1. Диалекmика возиикновения и развития СГУ, их место среди традииионных С.У и взаимодействие $c$ HUMU

САУ являются антропогенными системами, целевая функция которых призвана удовлетворять возрастаюшие пютребности практики. Несоответствие объективных потребностей реалыным возможностям и является движушей силой развитня САУ. Функционалыо-структурный подход в системном атгализе показывает, что возможности таких систем обусловлены их функцнонально- структурной организацией, а их развитие связано с расширением состава реализуемых ими функций, (нодробнее в [1]). Прн этом максимального эффекта можно ожидать от расширения состава системообразуюших фуцкций, но опо является нанболее трудоемким, в частности - наукоемким, т.к. затрагивает виелом как функциональную, так и структурную организацию системы, см. рис. 1. Последгяя включает в себя три иерархнческих уровня: алгоритмическую структуру, техннческую структуру и программно-техническую базу. Важно, что, обладая макснмальной огносительной самостоятельностью развития, шрограммно-техническая база интеллектуального ядра САУ, используя современные компьютерные технологии, спяла практически все ограпичения на сложность реатизуемых апгоритмов, т.е. на реализацию систем любой функциональной организацин.

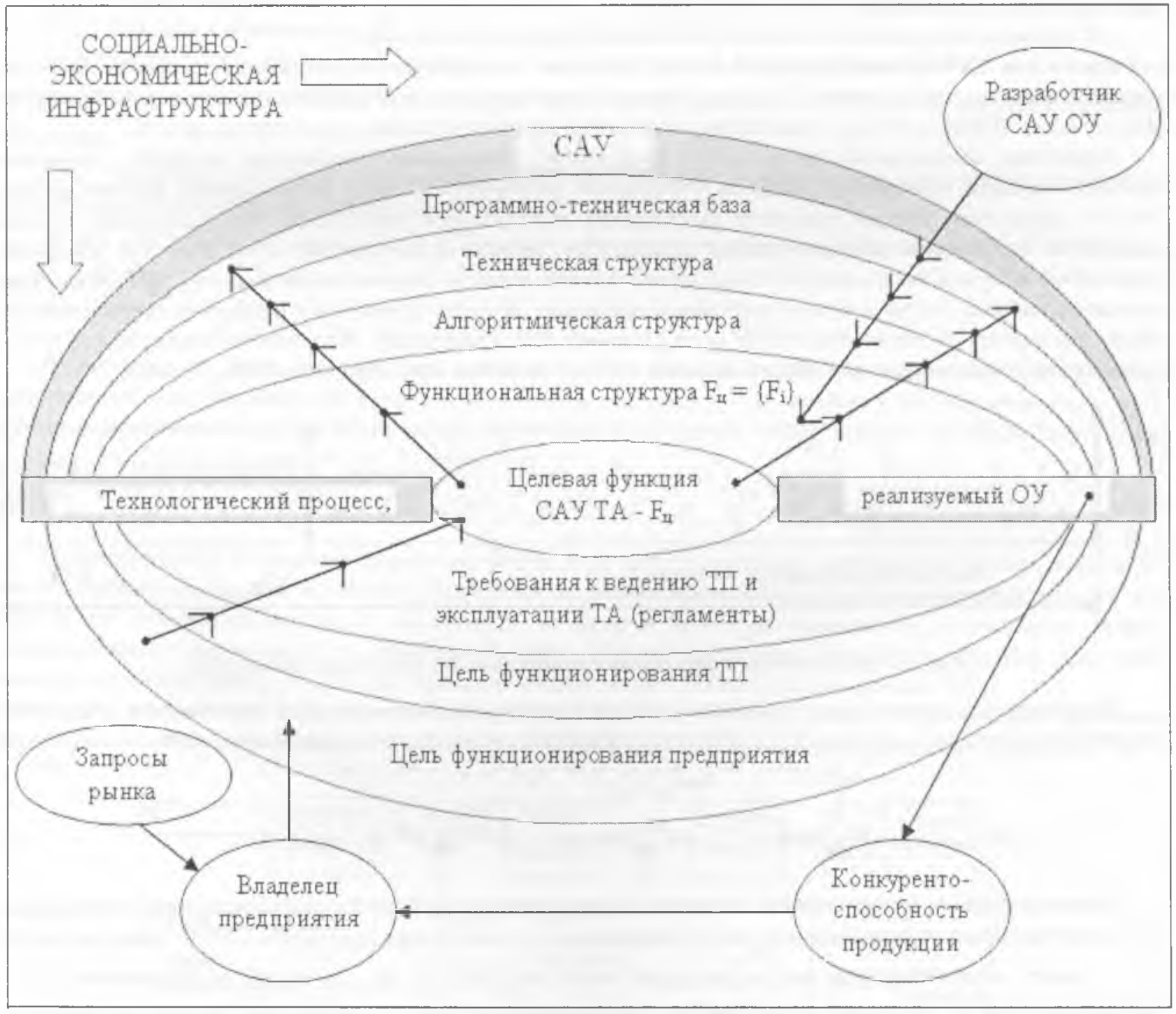

Рис. 1 - Схема формировани целевой функии САУ и ее функионально-структурнй организации 
Новая функция - функция гарантирования, как и традищонные для САУ функции регулирования, оптимизации, логического управления является системообразующей. Так, целью функции регулирования является обеспечение соответствия текущего состояния объекта заданному $-\bar{y}(t)=\bar{y}$ са $(t)$, функции оптимизации - достижение максимальной текущей эффективности работы объекта $-\bar{y}(t)=\vec{y}^{*}(t)=$ $\operatorname{argmax}\{Y(\vec{y}, t)\}$, функции гарантирования - достижение заданноц вероятности соблюдения ограничений регламента $\bar{y}(t)=\vec{y}^{a}(t)=\arg \left\{p\left(\hat{y}<\vec{y}^{a ̈}, t\right) \geq p\right.$ sä $\}$.

В [2] рассмотрена функциональная структура САУ с функцией гарантирования, где, в соответствии с ее статусом, она представлена на выспем иерархическом уровне декомпозиции целевой функции. Декомпозиция функции гарантирования конкретизирует задачи, которые целесообразно репать с ее использованием:

- коррекция текущих значений задающих переменных для соблюдения ограничений с гарантированной вероятностью

- определение допустимости оптимальных заданцых значений регламентированных перемениых по условию обеспечення гарантированной вероятности соблюдения ограничений, и при необходимости - перевод ТА в режим ее стабилизациц

- расцет (оптимизашия) настроек алгорнтмов регулирования по критерию минимума вероятности нарушения ограничений

- прогнозирование момента включения аварийной защиты и запуск упреждающего технологического останова ТА

Появление в функциональной организации САУ новой системообразующей функции дает основания рассматрнвать системы, реализуюшие эту функцию, как новый класс САУ, в данном случае - класс систем гарантируюшего управления.

2. Концепиия и теоретическая база систем гараптируюиезо управления

Реализация САУ с новой фунццией требует развития ее структурной организации и, прежде всего, ее верхнего иерархического уровня - алгоритмической структуры, т.е. конкретных структур и алгоритмов, ее реалзующих. Поскольку эта функция новая, то для этого потребуется новая теоретическая основа.

Концепция, составлягщая основу СГУ, предполагает непрерывное оценивание системой в реалыном времени текущего значения вероятности соблюдения регламента и такой корректировке режима работы объекта управления, которая обеспечит необходимое значение этой вероятности. Это оценивание требует разработки специальной модсли, которая позволит по оценкам характеристик доступных для измерсния переменных получить необходимую. Такая модель названа моделью нарушения регламента (МНР).B качестве ее основы выбрана теорня выбросов случайных процессов. В соответствии с ней нарушепне перемепюй х(t) своего регламента $D_{x}$, включающего (в обшем случае) два ограничения, «верхнее» и «нижнсе» $\left(x^{2 p}{ }^{*} x^{2 p-}\right)$ рассматривается как выброс слгучайного гроцесса $($ СП $x(t)$ за любое ограничение (событие $S)$, рис. 2 :

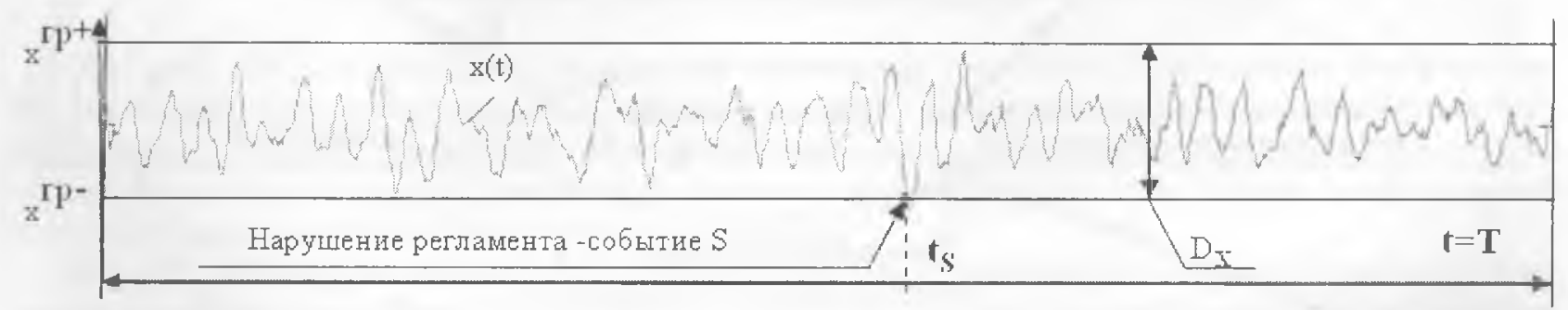

Рис. 2 - Иллюстрация парушения процессом $\mathrm{x}(\mathrm{t})$ своего регламента $\mathrm{D}_{\mathrm{x}}$

Выражение (1), связывающее средние количество нарушнений регламента $N_{5}$ с многомерной плотностью вероятности случайного процесса $p(\ldots)$, можно рассматривать как математическую основу MHP:

$$
\begin{aligned}
& N_{s}\left(x^{\bar{a} \partial-}, x^{\tilde{a} d t}, t_{0}, T\right)=N_{s}^{-}\left(x^{\tilde{a} \partial-}, t_{0}, T\right)+N_{s}^{+}\left(x^{\ddot{a d}+t}, t_{0}, T\right)=
\end{aligned}
$$

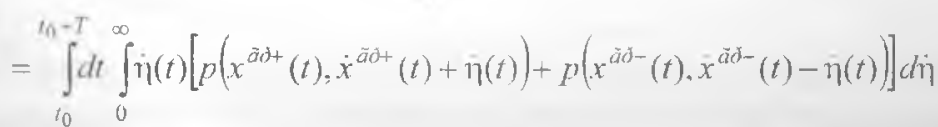

Непосредственное применение (1) для расчета управляющих воздействий в реальном времени невозможно. Его может позволить конкретизация условий применения (1), характерных для работы САУ. Главные из них: а) $x(t)$ - может рассматриваться, как нормальный, квазистационарный по случайной составляощей $\tilde{x}^{0}(t)$, дифференцируемый, по крайней мере, один раз, СП; б) характеристики СП необходимо заменить их оценками, рассчитываемыми на скользяших интервалах времени $T_{K C T}<<T$; в) события $S$ могут рассматриваться как поток 
редких событий, распределенных по закону Пуассона; г) количество событий $S$ на интервале $T-N,\left(x^{a \prime 4}, t_{0}, T\right)$ и их ицтенснвность $-n_{s}\left(x^{a j+1}, t\right)$ необходнмо сделать монотониыми функциями по аргументу $\left(x^{\Gamma P \pm}-x\right)$.

С их учетом выражение (1) принимает вид (2) и может рассматриваться как MHP (подробнее в [3]) достаточно общего вида :

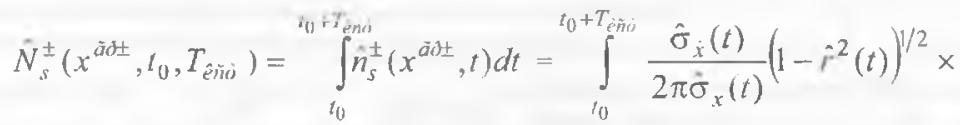

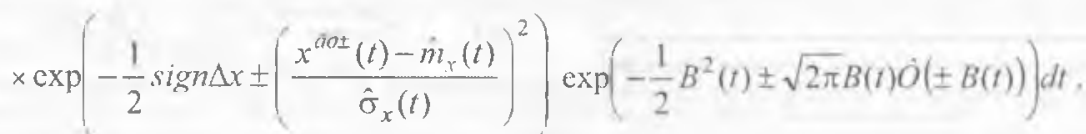

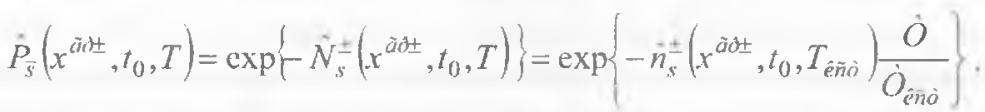

гце $B(t)=\left(1-\hat{r}^{2}(t)\right)^{-1 / 2}\left(\frac{\hat{m}_{\dot{r}}(t)}{\hat{\sigma}_{\hat{x}}(t)}+\operatorname{sign} \Delta x^{+} \frac{x^{\hat{a} \hat{\alpha}+ \pm}(t)-\hat{m}_{x}(t)}{\hat{\sigma}_{x}(t)} \vec{r}(t)\right)$

$\Delta x^{ \pm}=\left\{\begin{array}{l}x^{a j s-}-m_{x}, N_{s}^{+} \\ m_{x}-x^{a j-}, N_{s}^{-}\end{array} ;\right.$

$\dot{P}_{\bar{S}}\left(x^{\text {ais }}, t_{0}, T\right)$ - ошенка вероятности события $\bar{S}$ (отсутствия $\mathrm{S}$ на T);

$\operatorname{sign}($ ) - знаковая функция;

$\Phi(\ldots)-$ интеграл вероятности;

$\dot{m}_{r}(t), \dot{m}_{\dot{x}}(t), \hat{\sigma}_{x}(t), \hat{\sigma}_{x}(t), \hat{r}(t)$ - оценки на $T_{\kappa C T}$ характеристик CП $x(t)$, соответственно: математических ожиданий и среднеквадратических отклонений $x(t)$ и се псрвой производной $x(t)$, коэффициента корреляции $x(t)$ и $x(t)$;

$T_{K C т}$ - интервал времени, по возможности более короткий, для которого может быть принята гипотеза о квазистационарности перечисленных оценок.

Задать допустимые значения $N_{s}^{\tilde{a}}$ и $n_{s}^{u \pm}$ можно, введя понятие гарантированной вероятности собыгия $\bar{S}$ на $T-P_{7}^{\text {di }}\left(x^{\text {äd }}, T\right)$ :

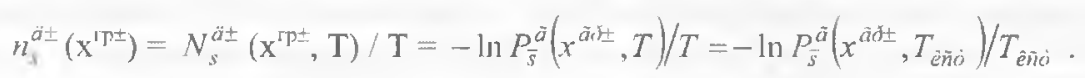

В частном, но очень важном для практики случае регламентированная переменная $x(t)$ является одновременно регулируемой, $x(t) \equiv y(t)$, с ограничением. например, $y^{\prime p}(t)$, а работа САР обеспечивает $m_{v} \approx y^{\prime \prime}$. Это дает возможность, решив обратную по отношению к (2) задачу, найти текущее предельно допустимое

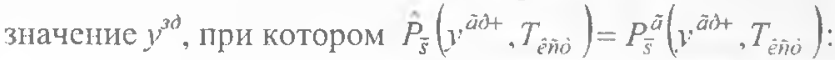

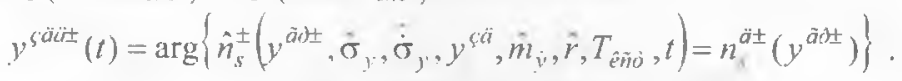

Многообразие СГУ отражаст ес классификания. В ее основу положены особснности: а) регламснтов; б) последствий их нарушений; в) объекта управления, и, прежде всего, характер изменения эффсктивности его работы при нзменениях режима; г) переменных, на которые наложены ограничения; д) вариантов расчета гарантирующего управлепия: e) конкретного вида модсли нарушения регламента, которая при этом используется (подробнее в $[4,5])$. Классификация создала основу для конкретизации вида СГУ.

На рис. 3 приведсны гримеры структурных схем замкнутых СГУ для случая, когда регламентированная переменная является регулируемой $x(t) \equiv y(t)$, а регламентом для $y(t)$ установлено ограничсние «сверху» $y^{2 p+}(t)$ :

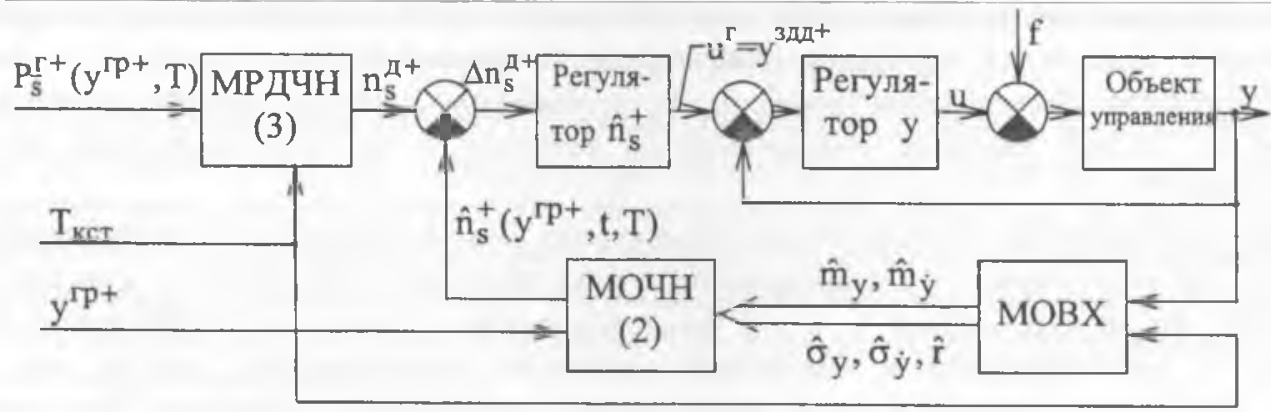




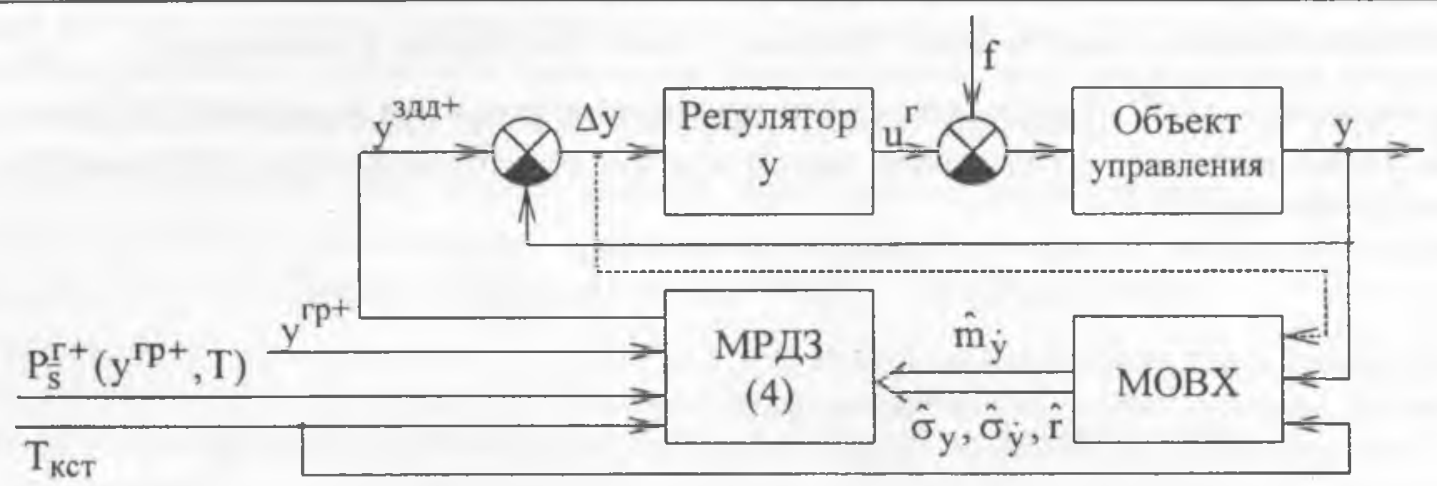

б)

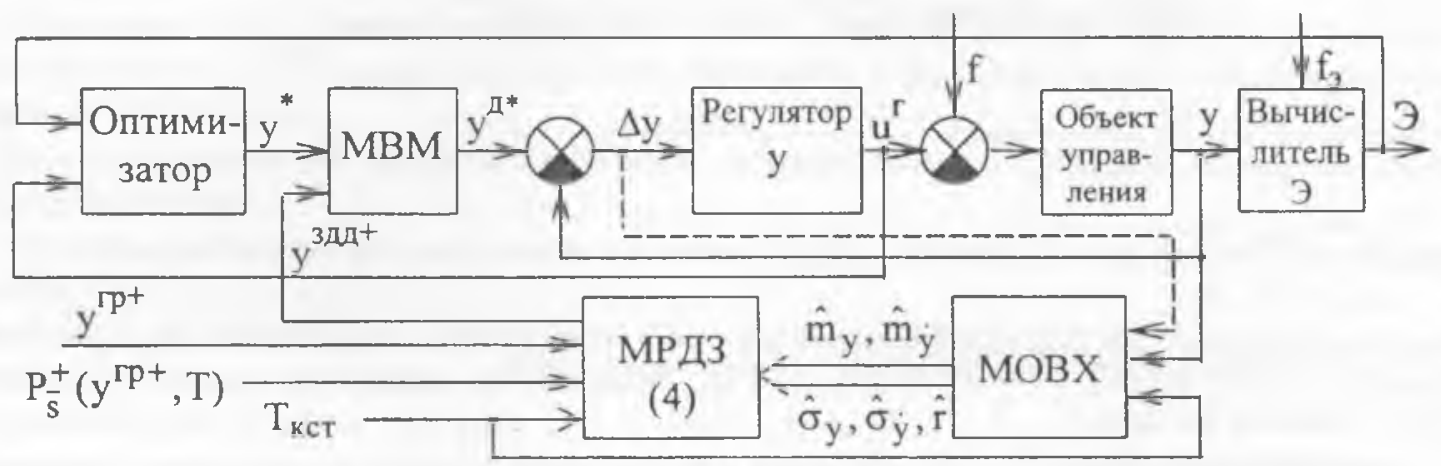

b)

Рис. 3 - Примеры структурных схем замкнутых СГУ

Алгоритмы гарантирующего управления (АГУ) реализуются модулями оценки частоты нарушений (МОЧН) регламенга либо расчета допустимого заданного значения (МРДЗ). Их основу составляет МНР, реализуемая в форме прямой или обратной задачи. Альтернативные вариапты АГУ строятся на частных случаях МНP (2), когда конкретизируются варианты модели изменения $m_{y}(l)$ регламентированной переменной $y(t)=m_{1}(t)+\bar{y}^{0}(t)$, как случайного процесса (в т.ч.-квазистационарной и квазипостоянной на $T_{\kappa C T}$, с гармопической составлягщей, нестационарной па $\left.T_{K C T}\right)$, и применения в АГУ процедур прогнозирования $m_{y}(t)$. Приведем здесь один пример АГУ (подробнее в [6-10]) для нестационарної модели $m_{y}(t)$ без ее прогнозирования:

$$
\begin{aligned}
& \hat{n}_{s}^{ \pm}\left(y^{\tilde{a} u t}, t\right)=\frac{\hat{\sigma}_{v}(t)}{2 \pi \dot{\sigma}_{y}(t)} \exp \left\{-\frac{1}{2} \operatorname{sign\Delta y}=\left(\frac{y^{\hat{a} \partial \pm}-\hat{m}_{y}(t)}{\hat{\sigma}_{v}(t)}\right)^{2}\right\} \times \\
& \times\left\{\exp \left(-\frac{\hat{m}_{y}^{2}(t)}{2 \dot{\sigma}_{i \cdot}^{2}(t)}\right) \mp \sqrt{2 \pi} \frac{\hat{m}_{j \cdot}(t)}{\dot{\sigma}_{Y \cdot}(t)} \hat{O}\left(\mp \frac{\hat{m}_{j}(t)}{2 \dot{\sigma}_{j \cdot}(t)}\right)\right\} \text {. }
\end{aligned}
$$

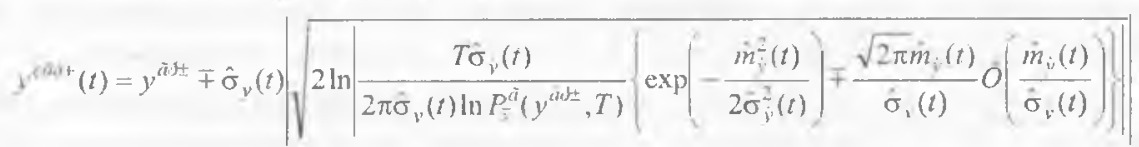

3. Обеспечелие устойчивости и сравиительный анализ СГУ с альтернативиыни варианпами алгоритмов

Полученные непосредственно по МНР АГУ требуют доработки, т.к. не учитывают одно принцигиально важное обстоятельство. Они создают в СГУ дополиительную обратпую связь («контур гараитирования»), вместе с которой появляются проблемы обеспечепия устойчивости этого контура и повышения его динамической точности. Исследования показали, что необходимые свойства контура гарантирования могут быть обеспечены за счет введения ограничений на величину и скорость нарастания гарантирующего управления $u^{\top}(t)=y^{\text {яdu }}$.

Для выбора перспективных к применению сравнительных были исследованы 14 альтернативных вариантов СГУ для двух структур: первая - с формированием гарантирующего управления в контуре стабилизации оценки частоты нарушений; вторая - $\mathrm{c}$ его непосредственным расчетом. Корректность сравнения их эффективности в установившихся и переходных процессах обеспечнвалась учетом всех характерных особенностей объектов и предварительной оптимизацией настроечных параметров. При этом пгараметры 
объскта брались: а) фиксированными; б) с «расчетными» диапазонами изменений, при которых и проводилась параметрическая оптимизация; в) «экстремальными», при которых «внутренняя» САР теряла устойчивость. Сравнение проводилось (подробнее в [7]) по двум осповным показателям - вероятности безаварийной работы $\dot{P}_{\bar{s}}\left(T_{\text {jй }}\right)$ и среднему удалению регулируемой переменной от своего ограничения $M\left[y^{2+}-y(t)\right] . \quad$ Их взаимопротиворечивость позволила выделить область компромиссов по Парето (ОКП). В ОКП вошли алгоритмы, в которых гарацтирующее управлешие рассчитываетя в контуре стабилизации оценки текущей ннтенсивност1 нарушений (рис. 3а). Вместе с тем, алгоритмы с его непосредственным расчетом (рис. 3б) обладают существенным, но неформализуемым пренмуществом - они значительно проше в применении, т.к. практически нс трсбуют настройки.

Нллюстрацию работы СГУ дает рис. 4. В его верхней части приведены условия работы САУ (изменения коордигатных и параметрических возмушений), а, ниже, работа в этих условиях трех вариаптов САУ: 1) обычная стабилизирующая САР с параметрически огтимальным ПИД-регулятором; 2) - система по п. 1, но с контуром гарантирования, т.е. СГУ со структурой по рис. 3б; 3)-система по п. 2, но со специальным регулятором перемснной структуры с прогнозированием в контуре регулирования. На интервалах времени от 150 до 200 и от 380 до 500 сочетание параметров объекта таково, что «внутренняя» САР с ПИД-регулятором становится неустойчивой в малом (экстрсмальные условия), но применение СГУ позволяет прсдотвратить $S$, те выбросы $y(t)$ за $y^{\text {क्p }}(t)=100$.

4.СГУ с оптинизаиией режимов раб́оты объектов управления

Задача оптимизации режимов работы объектов управления, функшия эффективгости которых дрейфует неконтролируемым образом, связана с нахождением и отслеживанием экстремума этой функции (см. рис. 5).

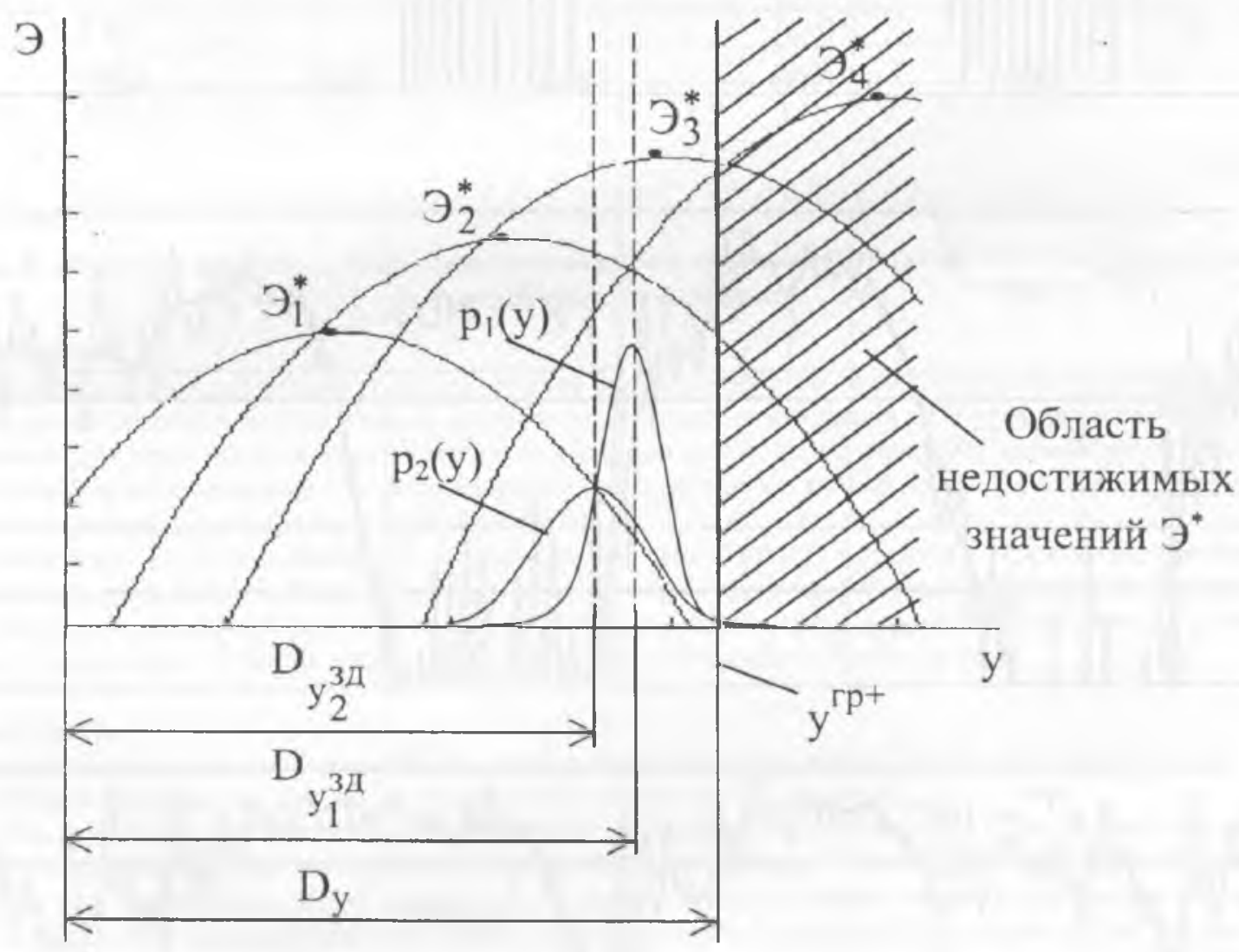

Рис. 5 - Дрейф экстремума функции зффективности и изенсния допустимих областей его понска при измененин точности стабилизации $\mathbf{y}(\mathbf{t})$

В том случае, когда на перемениые объекта наложены ограничения, то помимо функции оптимизации, одновременно, необходимо реализовать и функцню гарантированного соблюдения этих ограничений. Для этого алгоритмы гараптирования должны быть увязаны с алгоритмами поиска экстремума, см. рис. 3в. Традиционные системы экстремалыного регулирования (СЭР) часто используют алгоритмы с непрерывным поисковым сигналом и с запоминанием экстремума. Исследования взанмодействия алгоритмов гарантирования с такими алгоритмами оптимизации показали работоспособность и эффективность СЭР с гарантированием (СЭГР). Рис. 6 нллюстрирует сказанное (нодробнее в [11]). 

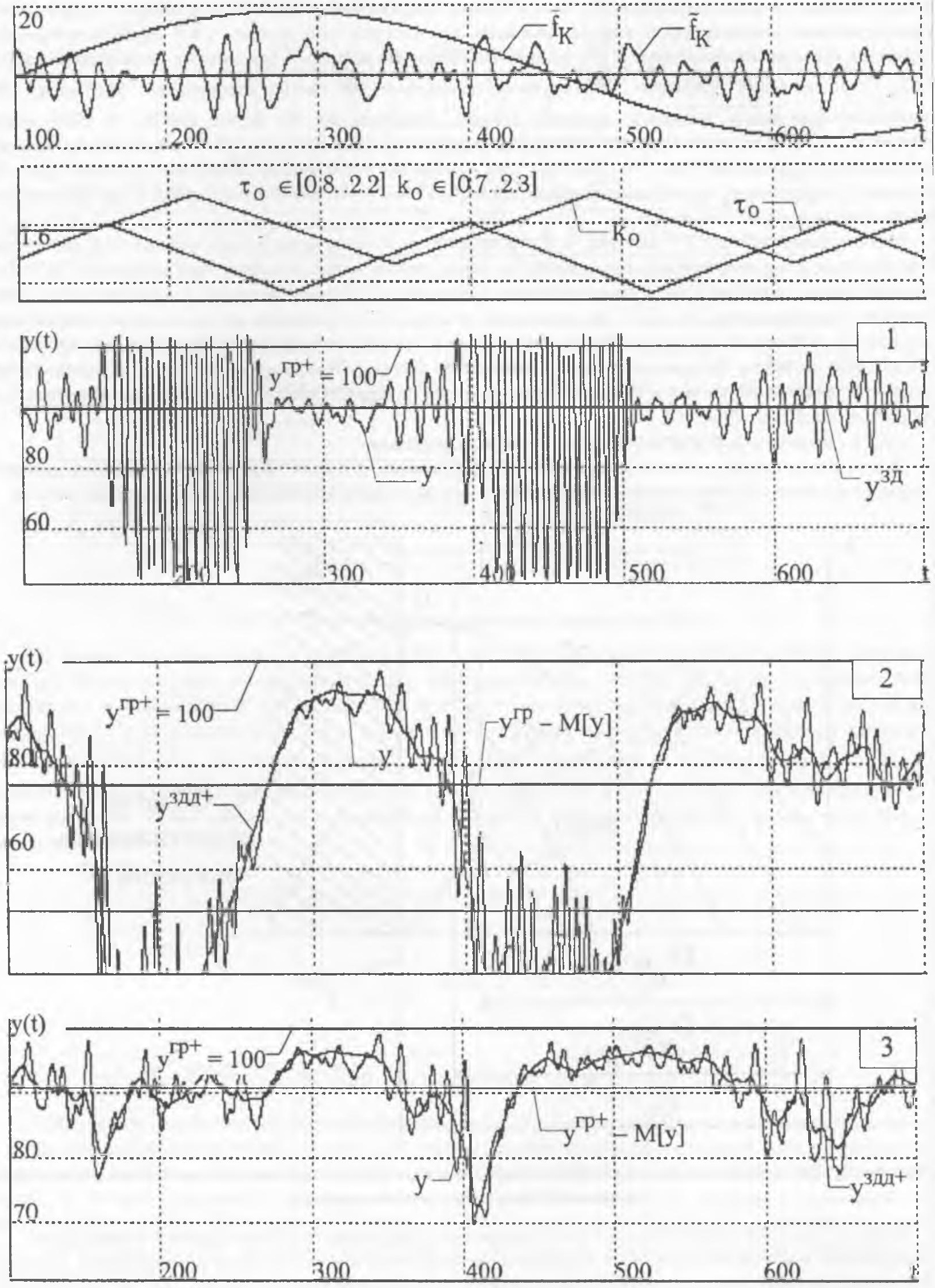

1) стабилизируюияая САР с ПНД-регулдятором;

2) СГУ со структурой, соответствуюией рис. 36, и ПИД-регуляторон в контуре регулирования;

3) СГУ по п. 2, по с регулятором переменной структуры и прогнозированием

Рис. 4 - Иллюстрация раб̆оты вариаптов САУ в экстремальных условиях 

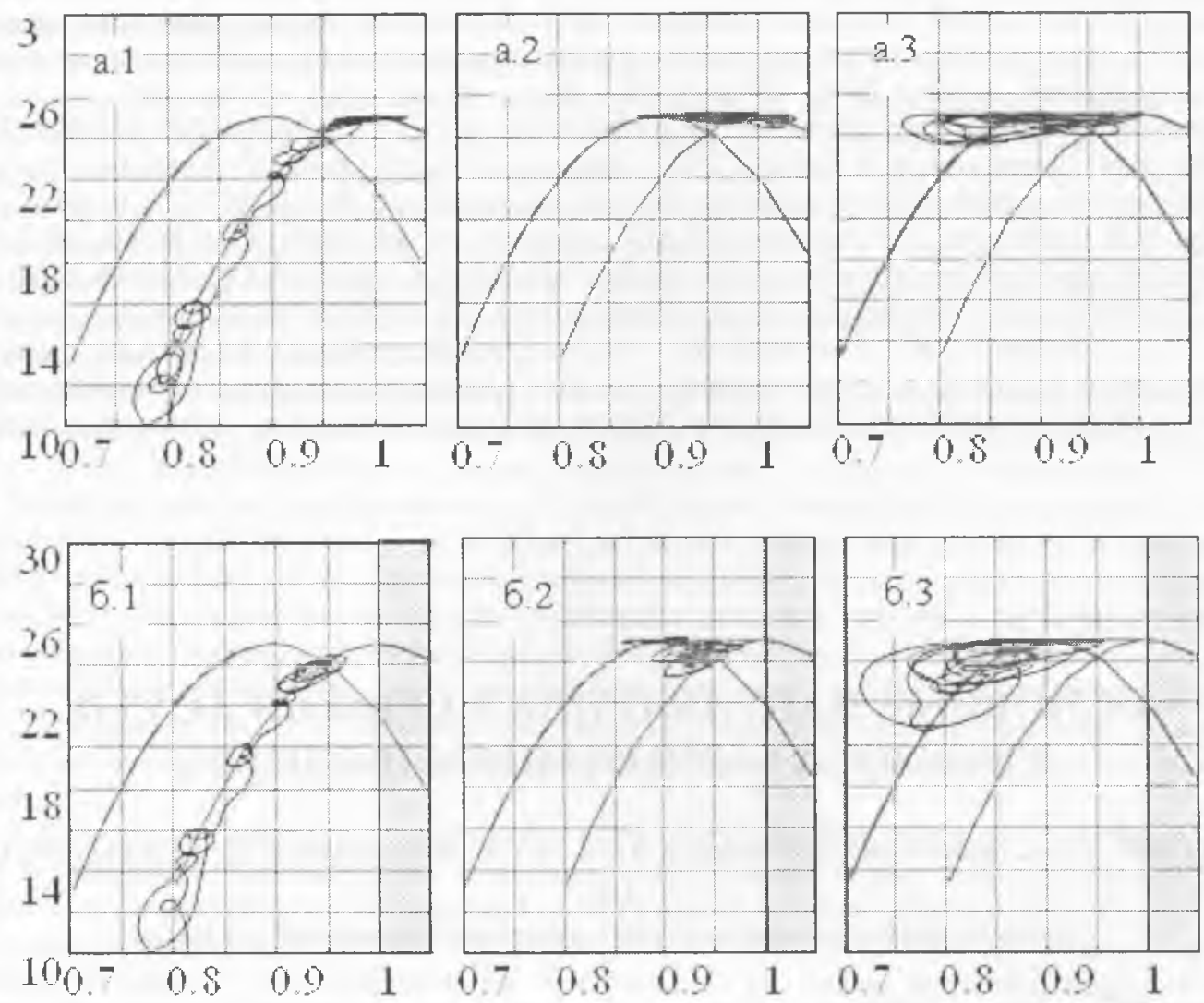

a.I. $\sigma .1-y^{*}=y^{2 p+}, \sigma_{f}^{2}=0,2 ; a .2 . \sigma .2-y^{*}=0.9 y^{p+}, \sigma_{f}^{2}=0,2 ; a .3, \sigma .3-y^{*}=0.9 y^{p+t}, \sigma_{f}^{2}=1$

\section{Рис. 6 - Фазовые портреты, иллюстрирующие работу обычной СЭР (а) и СЭГР (б) с непрерывным поисковым воздействием}

Закпиогене

Рассмотренное выше составляет только основы построениясистем гарантиругощего управления. Как и для других классов снстем, одной из главных научных задач совершенствования СГУ является повышение качества управления. Для этого могут использоваться как традиционные подходы, например параметрическая адаптация алгоритмов и прогнозирование, так и специфические, характерные только для СГУ, - например координация работы алгоритмов гарантирования и регулирования.

Применепие СГУ возможно и целесообразно для любых объектов управления, подверженных возмущениям, регламент которых включает в себя ограничения на режимы эксплуатации. Эффективность применения таких систем будет тем выше, чем тяжелей последствия нарушений регламента, и чем ближе наиболее эффективные режимы эксплуатации объекта приближаются к ограничениям.

\section{Литература}

1. Хобін В.А. Закономірності розвитку та принципи розробки ефективних систем автоматизаціі // В кн.: Наук. ир. / Одес. держ. акад. харч. техн. - Одеса, 1995. - Вип. 15. - С. 190-196.

2. Хобин В.А. Функция гарантирования в системах автоматического угравления // Всеукр. наук.-техн. журнал «Автоматизація виробничих процесів». - Київ, 2002. - № 1(14). - С. 145-150.

3. Хобін В.А. Імовірнісні моделі порушень регламенту технологічного процесу для систем гарантуючого управління // Удосконалення існуюччих та розробка нових технологій для харчової та зернопереробної промисловості: - 3б. наук. пр. / Одес. держ. акад. харч. техн. / М-во освіти України. - Вип. 1. - Одеса, 1999. - Вип. 19. - С. 234-237.

4. Хобин В.А. Системы гарантирующего управления: назначение, классификация, структура // Системний аналіз, управління і інформаційні технології: 3б. наук. пр. / Харків. держ. політех. ун-т. - Харків: ХДПУ, 1999. - Вип. 71. - С. 14-21.

5. Хобин В.А. Системы гарантирующего управления: структуры с расчетом уставок контурам регулирования // Пр. Мјжнар. конф. 3 автомат. управління (Львів. - 11 - 15 вересня 2000). - Т. 1 - Математичні проблеми управління, оптимізації та теорії ігор. - Львів, ДНдІ інформаційної інфраструктури, 2000. - С. 269-273.

6. Хобин В.А., Левинский В.М. Адаптивное управление технологическими гроцессами при ограничениях типа «аварийная ситуация» // В кн.: «Адаптивные системы автоматического управления» / Киев: Техника. 1986. - Вып. 14. - С. 84-90 
7. Хобин В.А., Степанов М.Т. Системы гарантируюшего управления: анализ замкнутых альтернативных структур // Тр. Одес. политех. ун-та: научньй и производственно-практический сборник по техническим и естественным наукам. - Одесса, 2001. - Вып. 3(15). - 305 с. - Яз. рус., укр. - С. 163-166.

8. Адаптиная система управления потенцианно опасным объектом: А.c. 1291926 СССР, МКИ G05 В $11 / 01 /$ В.А. Хобин, В.М. Левинский, А.И. Трач (СССР). - Заявлено 27.02.85; Опубл. 23.02.87, Бюл. № 7. - 10 с.

9. Адаптивная система управления потенциально опасным объектом: А.c. № 1423977 СССР, МКИ G05B 11/01 В.А. Хобин, В.М. Јевинский, Г.М. Редунов (СССР). - Заявлено 19.01.87; Опубл. 15.09.88, Бюл. № 34. - 14 с.

10. Адаптивная система управления потенциально опасным обьектом: А.с. 1513416 СССР, МКИ G05B, $11 / 01$ / В.А. Хобин, С.А. Воинова, В.М. Левинский (СССР). - Заявлено 05.11.87; Опублт. 07.10.89, Бюл. № 37. - 12 с.

11. Хобин В.А., Бабиков А.Ю. Исследование систем гарантирующего управления экстремальными нестационарными объектами с ограниченнями // Техніка в сільськогосподарському виробництві, галузеве машинобудування, автоматизація: 3б. наук. пр. / Кіровоград. держ. техн. ун-т. - Кіровоград. 2002. - Вип. 11. - C. 54-57.

УДК: $664.1: 65.011 .56$

\title{
ОСНОВНЫЕ НАПРАВЛЕНИЯ РАЗВИТИЯ АСУТП СВЕКЛОСАХАРНОГО ПРОИЗВОДСТВА
}

\author{
Жуковский Э.И., Д.Т.І., профессор; Скаковский ІО.М., к.т.н.; Витвицкий В.Д.; Шайкова О.І.; Бабков
}

A.B.

Одеская национальная академия пиневых технологий, г. Одесса

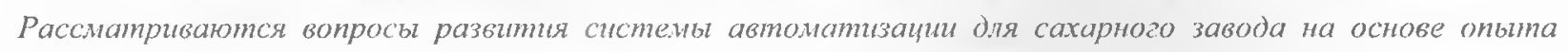
создания ряда систем на заводах Украины.

On the basis of experience of creation of some systems at Ukraine factories the questions of development the automation systems for sugar plant, are considered.
\end{abstract}

Ключевые слюва: системы автоматизации, оперативный учет, основные показатели, алгоритм, технологичсский участок, свеклосахарное производство.

\section{Введение}

На крупных предприятиях пищевой промышленности (ПП), в настоящес время, создаются современные системы автоматизацин класса АСУТII [1], строяшиеся на основе информационных сетевых решений. В частности, на сахарных заводах подоб́ные системы создаются в внде автоматизированных рабочих мест (АРМ) операторов технологических участков, с последующим объединением их в единую люкальную информацнонно-вычислительную сеть с АРМами сменного технолога (диспетчера), руководителей: главного технолога, главного ннженера, технического директора и т.п. Данные системы являются многоуровневыми, с точки зрения структуры и иерархии задач контроля и угравления. Комплекс задач, решаемых в составе таких многоуровневых систем, включает как традиционные задачи контроля, поддержания режимных парамстров в пределах регламентных зон, программно-логическоло управления процессами и аппаратами периодического действия, задачи оптимизации режимов, так и задачи огеративного учета, оценивания качества регулирования, а также координации работы технологических участков $[2,3]$.

Отличительной особенностью сахарной промышленности является сезонность, разветвленность и сложная структура сети технологических участков, существенное влияне нестационарности процессов, случайного характера возмущений на качество управления.

При автоматизации сложных объектов управления, таких как сахарный завод, возникает необходимость применения методов системного анализа для постросния сложных систем управления, обсспсчивающих высокие технико-экономические показатели функционирования системы. Системный подход позволяет найти оптимальные решения при выборе критериев управления отдельными подсистемами, обеспечить координацию рабогы элементов (технологических участков) технологических комплексов (ТК), управлясмых посредством сложных многоуровневых систсм управления, и только в этом случае удается обеспечить наилучшие технико-экономические показатели функшионирования автоматизированных ТК [4].

Традиционные критерии управления заводом, принятые в производстве сахара. при их наглядной интерпретации могут быть полезными не только при анализе успешности функционирования прсдприятия за сутки, декалу, месяц, но и гри текущем анализе внугрисменной работы. 